\title{
A New Approach to Improve Dynamic Characteristics of Digitally Controlled Buck-Boost DC-DC Converter
}

\author{
Fujio Kurokawa*, Taku Ishibashi*, Junya Sakemi* and Tadatoshi Babasaki** \\ * Nagasaki University, 1-14 Bunkyo-machi, Nagasaki-shi, Nagasaki, 852-8521 Japan \\ ** NTT, 9-11, Midori-Cho 3-Chome, Musashino-shi, Tokyo, 180-8585 Japan
}

\begin{abstract}
This paper presents a new digital control buckboost de-de converter with bias model to improve dynamic characteristics. The buck- boost converter needs to respond appropriately to changing input voltage and load change with wide input voltage. This approach makes adjustment to the bias value by input voltage and output current. As a result, it is revealed that not only the dynamic characteristics but also static characteristics can be improved and it is effective for wide range input voltage.
\end{abstract}

Index Terms-- Buck-boost dc-dc converter, Digital control, FIR filter

\section{INTRODUCTION}

At present, the analog control is used as a control system of the converter. However, the digital control has been attracting attention with the speeding up of the processing speed of the CPU and reducing the cost in recent years. While digital control has negative elements for response such as operation time and A-D conversion time, it is possible that the addition of the monitoring function, the control that is high in complexity, the part mark of the control circuit and the reduction of the fine adjustment point are enabled. Therefore the high function high-reliability, high promotion of efficiency converter are expected, and the digital control of the converter attracts attention [1]-[6].

The buck-boost dc-dc converter is used such as photovoltaic power generation, wind force power generation. However, these output voltages of electricity generated energy are unstable. Therefore, the buck-boost dc-dc converter is required because it has wide input voltage range.

This paper presents a new approach to improve the dynamic characteristics of the digitally controlled buckboost dc-dc converter. As new approach, the bias value controlled appropriately by detecting input voltage and output current. After reviewing the fundamental configuration of digitally controlled dc-dc converter with the minimum phase FIR filter control [7]-[8] and its operation principle, we analyze the dynamic

This work is supported in part by the Grant-in-Aid for Scientific Research (No. 21360134) of JSPS (Japan Society for the Promotion of Science) and the Ministry of Education, Science, Sports and Culture. characteristics of digitally controlled buck-boost dc-dc converter with changing load and input voltage. The key point of this paper is to describe the possibility to realize the high performance and stable digitally controlled buckboost dc-dc converter using DSP.

\section{OPERATION PRINCIPLE}

Figure 1 shows the block diagram of the digitally controlled buck type dc-dc converter using DSP. $E_{i}$ is the input voltage, $e_{o}$ is the output voltage and $i_{o}$ is the output current. $\mathrm{T}_{\mathrm{r}}$ is the main switch, $\mathrm{D}$ is the fly wheel diode, $\mathrm{L}$ is the energy storage reactor, $\mathrm{C}$ is the output smoothing capacitor and $R$ is the load. The output current $i_{o}$ is detected as the voltage $e_{s}$ by a sensing resistor $R_{s}$.

Figure 2 shows the configuration of the digital control circuit in Fig. 1.

$\mathrm{e}_{\mathrm{o}}, \mathrm{E}_{\mathrm{i}}$ and $\mathrm{e}_{\mathrm{s}}$ are sent to the A-D converter through the anti-aliasing filter and is converted into digital amount. The relation between the input $\mathrm{e}_{\mathrm{o}}$ and output values $\mathrm{N}_{\mathrm{eo}, \mathrm{n}}$ of the A-D converter is given by equation (1) when it approximately shows the linear expression by considering the width of the quantization to be small.

$\mathrm{N}_{\mathrm{eo}, \mathrm{n}}=\mathrm{G}_{\mathrm{eo}} \mathrm{e}_{\mathrm{o}}$

where $n$ denotes an $n$-th switching cycle and $\mathrm{G}_{\mathrm{eo}}$ is a gain of the A-D converter.

The digital amount $\mathrm{N}_{n}$ is sent to DSP. In DSP, the numerical value $\mathrm{N}_{\text {Ton }}$ that corresponds to the on-time interval $T_{\text {on }}$ is calculated. The relation between the ontime interval $\mathrm{T}_{\text {on }}$ and the numerical value $\mathrm{N}_{\text {Ton }}$ is shown as follows;

$\frac{\mathrm{T}_{\text {on }, \mathrm{n}+1}}{\mathrm{~T}_{\mathrm{S}}}=\frac{\mathrm{N}_{\mathrm{Ton}, \mathrm{n}+1}}{\mathrm{~N}_{\mathrm{Ts}}}$

where $\mathrm{N}_{T s}$ is a numerical value corresponding to the switching period $\mathrm{T}_{\mathrm{S}}\left(=1 / \mathrm{f}_{\mathrm{S}}\right)$. $\mathrm{N}_{\mathrm{TS}}$ is calculated in the PWM signal generation circuit which is composed of a digital comparator or a counter. According to the relation between the on-time interval $\mathrm{T}_{\text {on }}$ and the numerical value $\mathrm{N}_{\text {Ton }}, \mathrm{T}_{\text {on }}$ is generated. This $\mathrm{T}_{\text {on }}$ regulates the output voltage $e_{0}$.

The on-time interval $\mathrm{N}_{\text {Ton }}$ using the minimum phase FIR filter control circuit is represented as follows; 
$\mathrm{N}_{\text {Ton }, \mathrm{n}}=\mathrm{N}_{\mathrm{B}}-\mathrm{K} \sum_{\mathrm{i}=0}^{\mathrm{q}} \mathrm{h}_{\mathrm{i}}\left(\mathrm{N}_{\mathrm{eo}, \mathrm{n}-\mathrm{i}}-\mathrm{N}_{\mathrm{R}}\right)$

where $\mathrm{K}$ is proportional gain, $\mathrm{h}_{\mathrm{i}}$ denotes the digital filter coefficients, $q$ is the amount of the sampling points and $\mathrm{N}_{\mathrm{R}}$ is reference value.

In conventional method, it operates FIR filter control by detecting only $\mathrm{e}_{\mathrm{o}}$. Furthermore bias value $\mathrm{N}_{\mathrm{B}}$ is fixed.

In this approach, it operates FIR filter control and controls bias value appropriately by detecting $E_{i}$ and $e_{s}$. These analog values are converted to digital values in AD converter.

$$
\begin{aligned}
\mathrm{N}_{\text {Ei }, \mathrm{n}} & =\mathrm{G}_{\mathrm{Ei}} \mathrm{E}_{\mathrm{i}} \\
\mathrm{N}_{\mathrm{es}, \mathrm{n}} & =\mathrm{G}_{\mathrm{es}} \mathrm{e}_{\mathrm{s}} \\
& =\mathrm{G}_{\mathrm{es}} \mathrm{i}_{\mathrm{o}} \mathrm{R}_{\mathrm{s}}
\end{aligned}
$$

$\mathrm{N}_{\mathrm{B}}$ is decided by expression (6).

$N_{B}=\frac{\left(2^{\text {Nbit }}-1\right)\left(2 E_{o}^{*}+E_{i}-\sqrt{E_{i}^{2}-4 r \cdot I_{o}\left(E_{i}+E_{o}^{*}\right)}\right)}{2\left(E_{i}+E_{o}^{*}\right)}+N_{B 1}$

where $\mathrm{E}_{\mathrm{O}}{ }^{*}$ is desired output voltage and $\mathrm{N}_{\text {bit }}$ is the number of bits of A-D converter. There is $\mathrm{N}_{\mathrm{B} 1}$ to make up for losses for parasitic resistance in circuit.

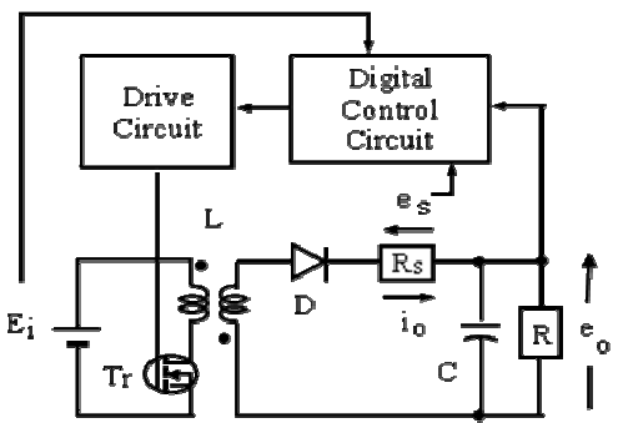

Fig. 1 Diagram of the digitally controlled buck-boost type dc-dc converter using DSP.

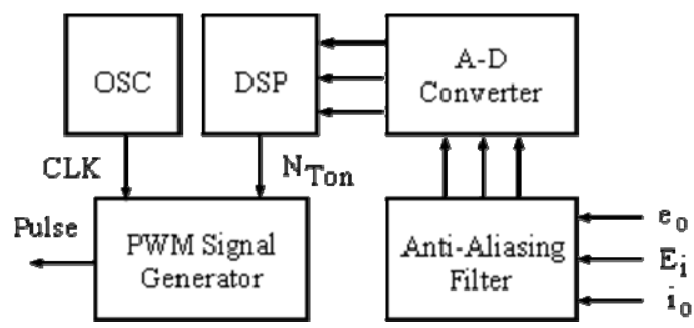

Fig. 2 Digital control circuit.

\section{TRANSIENT RESPONSE}

\section{A. Load change}

Figures 3 through 5 show the simulated transient response of the dc-dc converter with digital control in step change of the load resistor R from $100 \Omega$ to $10 \Omega$ in each condition. The simulator is PSIM. In these figure,
Tst is the time to settle within $1 \%$ of the rated output voltage. The switching frequency is $100 \mathrm{kHz}$. The number of the bits of the digital control circuit is 11 bits. The circuit parameters are desired output voltage $\mathrm{E}_{\mathrm{o}} *=10 \mathrm{~V}$, $\mathrm{L}=260 \mu \mathrm{H}, \mathrm{C}=1400 \mu \mathrm{F}$ and the leakage inductance is $4 \mu \mathrm{H}$. gain $\mathrm{K}$ is fixed to 8 . In conventional method, the bias value $N_{B}$ is fixed to 1180 . In new approach, $N_{B}$ depends on $E_{i}$ and $I_{o}, N_{B 1}$ is 69 . These bias numbers are set to output voltage become $10 \mathrm{~V}$ when input voltage is $10 \mathrm{~V}$ and load resistor $\mathrm{R}$ is $10 \Omega$. The $\mathrm{r}$ is 0.4 . Little $\mathrm{r}$ become less effective, but too large $\mathrm{r}$, it makes losing control.

As for the parameter of FIR filter, pass band frequency is $2.5 \mathrm{kHz}$, transition band frequency is $1.0 \mathrm{kHz}$ and stop band frequency is $3.5 \mathrm{kHz}$.

At first, as static characteristics in new approach, it follows that output voltage is nearly desired output voltage $\mathrm{E}^{*}$ in every situation, $\mathrm{E}_{\mathrm{i}}$ is $5,10,15 \mathrm{~V}$ and $\mathrm{R}$ is 10 and $100 \Omega$.

Figure 3 shows transient response in step change load when $\mathrm{E}_{\mathrm{i}}$ is $5 \mathrm{~V}$ and (a) is conventional method, the under shoot is $118 \mathrm{mV}$, and transient time $\mathrm{T}_{\mathrm{st}}$ is $2.1 \mathrm{~ms}$. In figure 3 (b) new approach, the under shoot is $249 \mathrm{mV}$ and transient time $\mathrm{T}_{\text {st }}$ is $5.1 \mathrm{~ms}$.

Figure 4 is $E_{i}=10 \mathrm{~V}$ and (a) is conventional method. The under shoot is $133 \mathrm{mV}$, and transient time $\mathrm{T}_{\mathrm{st}}$ is $1.0 \mathrm{~ms}$. In figure4 (b) new approach, the under shoot is $102 \mathrm{mV}$ and transient time $\mathrm{T}_{\text {st }}$ is $0.8 \mathrm{~ms}$.

In figure $5, \mathrm{E}_{\mathrm{i}}=15 \mathrm{~V}$ and (a) is conventional method. The under shoot is $116 \mathrm{mV}$, and transient time $\mathrm{T}_{\mathrm{st}}$ is $0.7 \mathrm{~ms}$. In figure 5 (b), the under shoot is $158 \mathrm{mV}$ and transient time $\mathrm{T}_{\mathrm{st}}$ is $0.7 \mathrm{~ms}$.

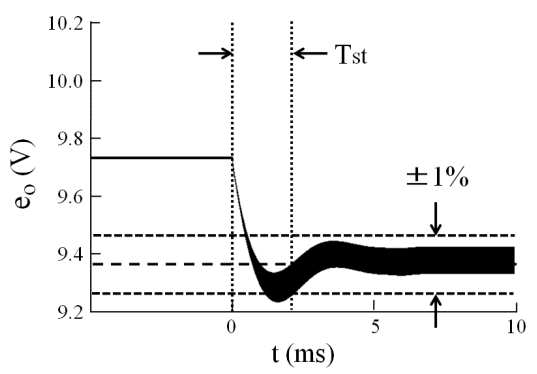

(a) Conventional method

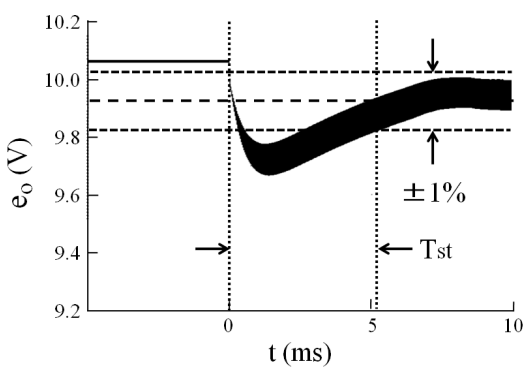

(b) New approach

Fig. 3 Transient response in step change load when $\mathrm{E}_{\mathrm{i}}$ is $5 \mathrm{~V}$. 


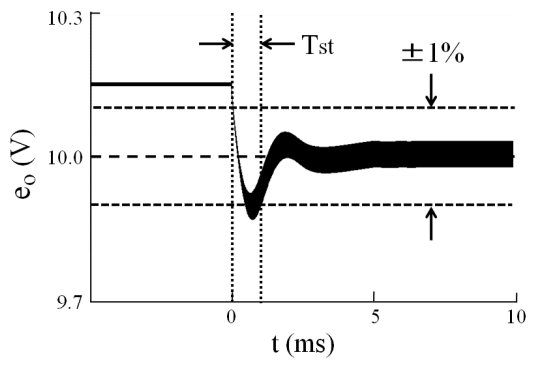

(a) Conventional method

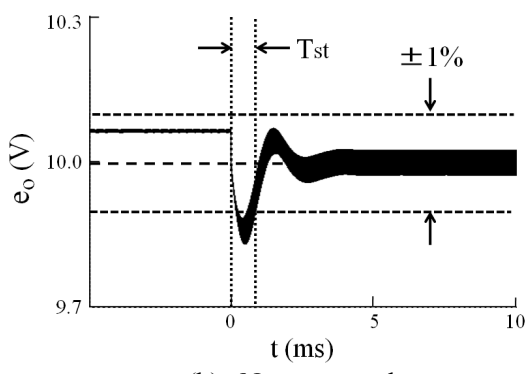

(b) New approach

Fig. 4 Transient response in step change load when $\mathrm{E}_{\mathrm{i}}$ is $10 \mathrm{~V}$

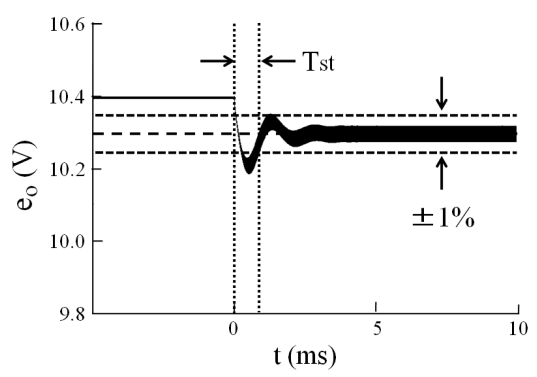

(a) Conventional method

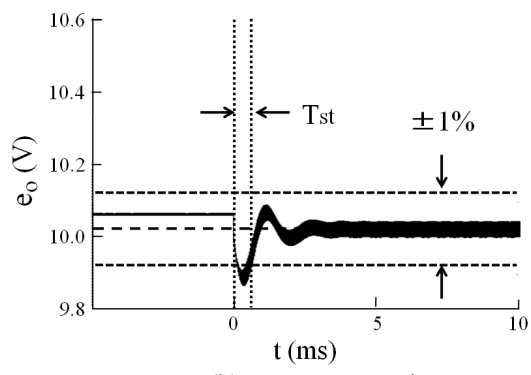

(b) New approach

Fig. 5 Transient response in step change load when $\mathrm{E}_{\mathrm{i}}$ is $15 \mathrm{~V}$.

\section{B. Input voltage change}

Figures 6 through 9 show the simulated transient response of the dc-dc converter with digital control in step change of the input voltage. The load resistor $\mathrm{R}$ is $10 \Omega$. The other conditions are same as the last time.

Figure6 shows transient response in step change input voltage from 5 to $10 \mathrm{~V}$ and (a) is conventional method, the over shoot is $293 \mathrm{mV}$, and transient time $\mathrm{T}_{\text {st }}$ is $2.4 \mathrm{~ms}$. In figure6 (b) new approach, the over shoot is $209 \mathrm{mV}$ and transient time $\mathrm{T}_{\text {st }}$ is $0.9 \mathrm{~ms}$.
In figure 7, $\mathrm{E}_{\mathrm{i}}$ changes from 10 to $5 \mathrm{~V}$ and (a) is conventional method. The under shoot is $131 \mathrm{mV}$ and transient time $\mathrm{T}_{\mathrm{st}}$ is $2.6 \mathrm{~ms}$. In figure 7 (b), the under shoot is $144 \mathrm{mV}$ and transient time $\mathrm{T}_{\mathrm{st}}$ is $2.9 \mathrm{~ms}$.

In figure $8, \mathrm{E}_{\mathrm{i}}$ changes from 10 to $15 \mathrm{~V}$. In conventional method, the under shoot is $130 \mathrm{mV}$ and transient time $\mathrm{T}_{\text {st }}$ is $1.0 \mathrm{~ms}$. In figure 8 (b), the under shoot is $73 \mathrm{mV}$ and since the output voltage does not exceed $1 \%, \mathrm{~T}_{\text {st }}$ is $0 \mathrm{~ms}$.

In figure $9, \mathrm{E}_{\mathrm{i}}$ changes from 15 to $10 \mathrm{~V}$. In conventional method, the under shoot is $293 \mathrm{mV}$ and transient time $\mathrm{T}_{\text {st }}$ is $1.4 \mathrm{~ms}$. In figure9 (b), the under shoot is $63 \mathrm{mV}$ and since the output voltage does not exceed $1 \%, \mathrm{~T}_{\text {st }}$ is $0 \mathrm{~ms}$.

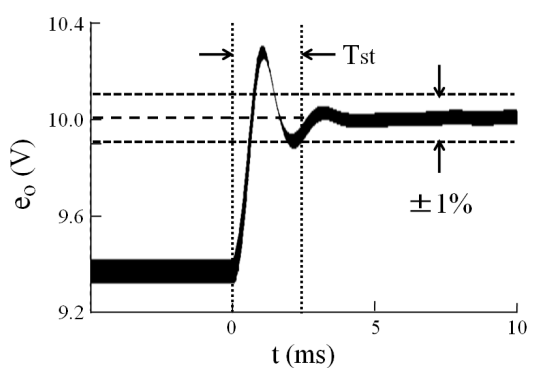

(a) Conventional method

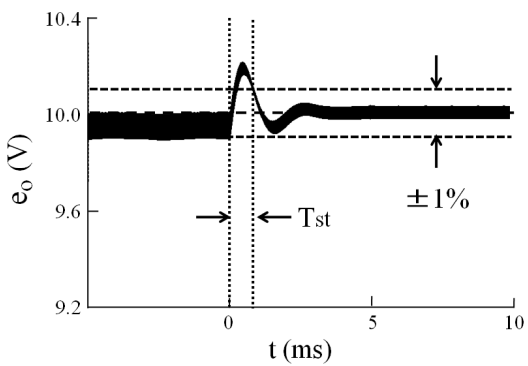

(b) New approach

Fig. 6 Transient response in step change input voltage from 5 to $10 \mathrm{~V}$.

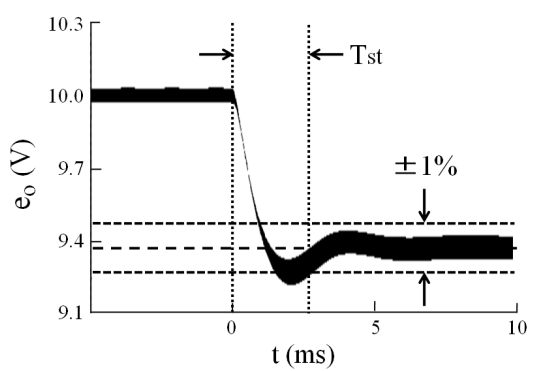

(a) Conventional method

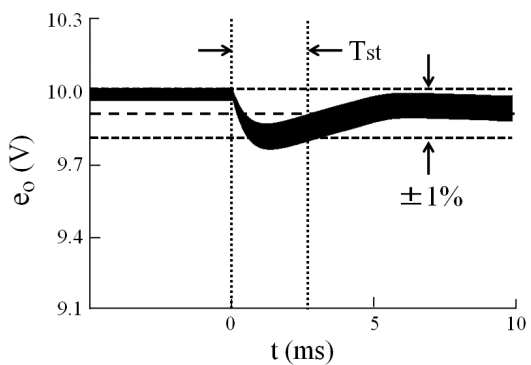

(b) New approach

Fig. 7 Transient response in step change input voltage from 10 to $5 \mathrm{~V}$. 


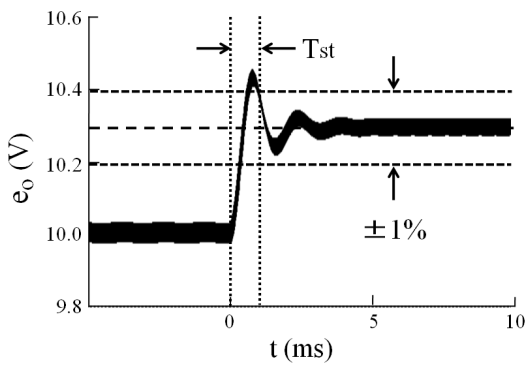

(a) Conventional method

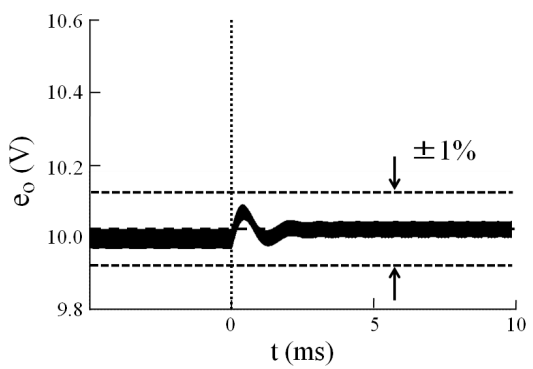

(b) New approach

Fig. 8 Transient response in step change input voltage from 10 to $15 \mathrm{~V}$.

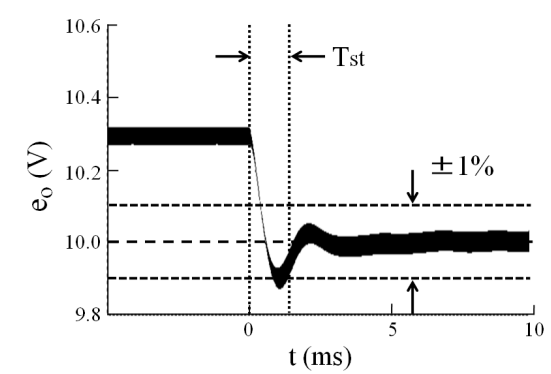

(a) Conventional method

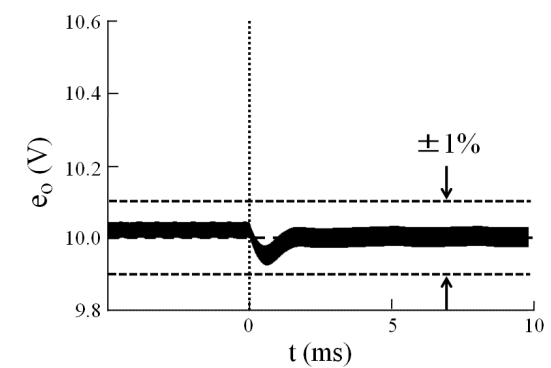

(b) New approach

Fig. 9 Transient response in step change input voltage from 15 to $10 \mathrm{~V}$.

\section{CONCLUSIONS}

The converter is controlled with digital FIR filter. The feed buck of conventional method is only detecting output voltage. As a new approach, bias value in DSP is controlled appropriately by detecting input voltage and output current.

We compared it with a conventional method under step change load and input voltage.

As a result, the static characteristics are improved in all conditions. Furthermore, the dynamic characteristics could be also improved in many cases.

We confirm that these results are useful to realize the next generation model of the switching power supply for the renewable energy source.

\section{REFERENCES}

[1] D. Maksimovic, R. Zane and R. Erickson: "Impact of digital control in power electronics," Proc. of ISPSD, pp. 13-22, May 2004.

[2] H. Hu, V. Yousefzadeh and D. Maksimovic: "Nonlinear control for improved dynamic response of digitally controlled dc-dc converters," IEEE PESC Record, pp. 2584-2590, June 2006.

[3] V. Yousefzadeh, A. Babazadeh, B. Ramachandram and E. Alarcon: "Proximate time-optimal digital control for dc-dc converters,” IEEE PESC Record, pp. 124-130, June 2007.

[4] F. Kurokawa, K. Tanaka and H. Eto: "Performance characteristics of switching dc-dc power converter with static model reference," Proc. of ICEMS, pp. 1-5, Nov. 2006.

[5] P. T. Krein: "Digital control generations digital controls for power electronics through the third generation," Proc. of IEEE PEDS, pp. P1-P5, Nov. 2007.

[6] D. Plaza, R. De Keyser and J. Bonilla:"Model Predictive and Sliding Mode Control of a Boost Converter," Proc. of IEEE SPEEDAM, pp.37-42, June 2008.

[7] B. Mulgrew, P. Grant and J. Thompson: "Digital signal processing," Macmillan Press Ltd., London, 1999.

[8] Fujio Kurokawa and Taku Ishibashi, "Dynamic Characteristics of Digitally Controlled Buck-Boost DCDC Converter," IEEE PEDS, pp1-6, Oral4_3A_4, Nov. 2009. 